\title{
Increasing trend of sensitization to Methylchloroisothiazolinone/methylisothiazolinone (MCl/MI)
}

\author{
Maria Antonieta Rios Scherrer ${ }^{1}$
}

Vanessa Barreto Rocha ${ }^{1}$

DOI: http://dx.doi.org/10.1590/abd1806-4841.20142852

\begin{abstract}
Recent reports have shown increased sensitization to Methylchloroisothiazolinone/methylisothiazolinone. We report a retrospective study conducted at the Hospital das Clínicas - UFMG, based on the results of patch tests with the Brazilian standard series, performed on referred patients. The positive results in 359 patients from November 2009 to October 2012 were analyzed and compared with the previous data collected from March 2006 to October 2009 (447 patients). The data showed 11.14\% sensitization to Methylchloroisothiazolinone/ methylisothiazolinone during 2009-2012, contrasting with the previous period (3.35\%). A positive association was found between its positivity and the period of 2009-2012.
\end{abstract}

Keywords: Dermatitis, allergic contact; Epidemiology; Preservatives, pharmaceutical

Methylchloroisothiazolinone/methylisothiazolinone (MCI/MI) is a preservative mixture at a fixed combination (ratio 3/1), which is commonly used in cosmetic and industrial applications and can be found in cosmetics, especially shampoos, dermatological products, mainly sunscreens, household cleaning products, paints, moist toilet paper, metalworking fluids. ${ }^{1-4}$

It is also known as Euxyl K 100 or Kathon CG. In the USA, where it was first introduced in 1980, it is permitted as a preservative for rinse-off products at $15 \mathrm{ppm}$ and for leave-on products at $7.5 \mathrm{ppm}$. In Europe, it was used initially in the mid-1970s, and is employed today at $15 \mathrm{ppm}$ for leave-on or rinse-off products. In Japan, it is permitted only for rinse-off products, at $15 \mathrm{ppm}$. In Brazil, it is permitted at $0.0015 \%(15 \mathrm{ppm})$ and is tested at $0.5 \%$ in petrolatum (Brazilian standard series). ${ }^{5}$

Recent reports have shown an increase in sensitization to both $\mathrm{MCI} / \mathrm{MI}$ and $\mathrm{MI}$ by itself. ${ }^{1,4}$ The global frequency of sensitization to $\mathrm{MCI} / \mathrm{MI}$ remained constant at around $2.1 \%$ from 1998-2009, but increased to $3.9 \%$ in 2011.,2,3 North American Contact Dermatitis Group data from 2009-2010 revealed a frequency of $2.5 \%$ among 4,032 patients tested. The allergen was the fifth most positive preservative and had the highest relevance of all. The definite and probable relevance was $54.6 \%$, whereas the possible relevance was $38.9 \%$. Methylisothiazolinone (MI) was the American Contact Dermatitis Society Contact Allergen of the Year for 2013 because its use in cosmetics and toi- letries is rising. ${ }^{6}$ It is suggested that primary sensitization to $\mathrm{MI}$ led to a subsequent rise in $\mathrm{MCI} / \mathrm{MI}$ reactions. ${ }^{1}$

A retrospective study was carried out based on the results of patch tests with the Brazilian standard series, performed on contact dermatitis referred patients. They were patch tested to the Brazilian Standard Tray (FDA Allergenic/Immunotech, Rio de Janeiro, Brazil) with a standardized technique, using Finn Chambers (Epitest Ltd Oy, Tuusula, Finland) on Scanpor tape (Norgeplaster Alpharma AS, Vennesla, Norway). Readings occurred on days two and four. The positive results in 359 patients from November 2009 to October 2012 were analyzed and compared with the previous data collected from March 2006 to October 2009 (447 patients). For descriptive characterization of the patient population, the MOHALFA index (an acronym for male, occupational, atopic, hand, leg or face dermatitis and age $>40$ ) was used.

The data showed $11.14 \%$ sensitization to $\mathrm{MCI} / \mathrm{MI}$ during 2009-2012, contrasting with the previous period (3.35\%). A positive association between $\mathrm{MCI} / \mathrm{MI}$ positivity and the period 2009-2012 $(\mathrm{OR}+3,61 \mathrm{CI} 95 \%$ 1.91-7.16 $\mathrm{p}<0,001)$ was detected (the analyses were obtained with the R program, version 2.13.0) (Table 1).

Positive reactions were observed equally in caucasians, black and mulattos. The most afflicted occupations were cleaners and housewives, which were linked to wet work and use of household products,

\footnotetext{
Received on 08.06.2013.

Approved by the Advisory Board and accepted for publication on 20.07.2013.

Work performed at the Ambulatório de Dermatologia do Hospital das Clínicas da Universidade Federal de Minas Gerais (UFMG) - Belo Horizonte (MG), Brazil. Conflict of interest: None

Financial funding: None

Universidade Federal de Minas Gerais (UFMG) - Belo Horizonte (MG), Brazil.
} 
Table 1: Differences in the MCI/MI positive reactions during the studied periods analyzed by exact Fisher's test and Odds ratios ( $\mathrm{CI}=95 \%)$

\begin{tabular}{lccll}
\hline Period & N & Positive & $\%$ & OR \\
\hline 2006-09 & 447 & $\begin{array}{c}\text { reaction } \\
15\end{array}$ & 3.35 & $\begin{array}{l}3,61(\mathrm{Cl} 95 \% 1,91-7,16) \\
\text { p }<0,001\end{array}$ \\
$2009-12$ & 359 & 40 & 11.14 & \\
\hline
\end{tabular}

while $27.5 \%$ of the patients showed occupational correlation with sensitization. The period of evolution of the dermatitis was one year in $60 \%$ of the patients. $82.5 \%$ of the patients presented disseminated lesions affecting more than three body areas. The most affected sites were the legs $(80 \%)$ and feet $(62.5 \%)$, followed by the scalp (57.5\%) and neck (50\%). $42.5 \%$ of the patients had lesions on the hands and $27.5 \%$ on the face.

In both groups women were more affected and their ages were similar, but the first group was more associated with occupational exposure (53.3\%) (Table 2).

Table 2: MOAHLFA index for the investigated populations

\begin{tabular}{lcccl}
\hline MOAHLFA & 2006-2009 & Period & 2009-2012 & Period \\
\hline & $\%$ & N 15 & \% & N 40 \\
\cline { 2 - 5 } $\begin{array}{l}\text { Men } \\
\begin{array}{l}\text { Occupational } \\
\text { dermatitis }\end{array}\end{array}$ & 53.3 & 5 & 12.5 & 5 \\
$\begin{array}{l}\text { Atopic } \\
\text { dermatitis }\end{array}$ & 26.6 & 4 & 17.5 & 7 \\
$\begin{array}{l}\text { Hand } \\
\text { dermatitis }\end{array}$ & 80 & 12 & 42.5 & 17 \\
$\begin{array}{l}\text { Leg dermatitis } \\
\text { Face dermatitis }\end{array}$ & 20 & 3 & 80 & 32 \\
Age> 40 & 53.6 & 7 & 27.5 & 11 \\
\hline
\end{tabular}

\section{REFERENCES}

1. Geier J, Lessmann H, Schnuch A, Uter W. Recent increase in allergic reactions to methylchloroisothiazolinone/methylisothiazolinone: is methylisothiazolinone the culprit? Contact Dermatitis. 2012;67:334-41.

2. Mowad CM. Methylchloroisothiazolinone revisited. Am J Contact Dermat. 2000;11:115-8.

3. Lundov MD, Thyssen JP, Zachariae C, Johansen JD. Prevalence and cause of methylisothiazolinone contact allergy. Contact Dermatitis. 2010;63:164-7.

4. Urwin R, Wilkinson M. Methylchloroisothiazolinone and methylisothiazolinone contact allergy: a new epidemic. Contact Dermatitis. 2013;68:253-5.

5. Grupo Brasileiro de Estudo em Dermatite de Contato; Sociedade Brasileira de Dermatologia. Departamento Especializado de Alergia. Estudo multicêntrico para elaboração de uma bateria-padrão brasileira de teste de contato. An Bras Dermatol. 2000;75:147-56.

6. Castanedo-Tardana MP, Zug KA. Methylisothiazolinone. Dermatitis. 2013;24:2-6.
The final diagnosis was angry back in 7.5\%, allergic contact dermatitis to Kathon in $57.5 \%$ and allergic contact dermatitis to Kathon and other contactants in $35 \%$ of the patients. The main source was household products and cosmetics.

Our data revealed an increase in the prevalence of $\mathrm{MCI} / \mathrm{MI}$, especially after 2009, linked to exposure to cosmetic, household and industrial products, which explains the clinical features described above and confirms previous European studies.

Isothiazolinones do not always cross-react and therefore, allergy to one isothiazolinone does not mean sensitivity to the entire group. Patients sensitized to MI also react to MCI, while the opposite does not necessarily apply. Nevertheless, a study with a stratified data analysis revealed pronounced increases in reactivity to $\mathrm{MCI} / \mathrm{MI}$ and $\mathrm{MI}$ in females, face dermatitis patients and patients tested for suspected cosmetic intolerance. In order to understand the scale of the problem, MI should be considered as a potential suspect allergen in patients sensitized to $\mathrm{MCI} / \mathrm{MI}$, and MI should be included in the standard trays.

In conclusion, the positivity to $\mathrm{MCI} / \mathrm{MI}$ in this series was associated with: females, mainly housewives and cleaners; the presence of dermatitis of at least 1 year's evolution; and disseminated lesions affecting especially the legs.]

\author{
MAILING ADDRESS: \\ Maria Antonieta Rios Scherrer \\ Rua Rio Grande do Norte, 726 sl 804 \\ 30.130-131 - Belo Horizonte - MG \\ Brazil \\ E-mail:mariariosscherrer@hotmail.com
}

How to cite this article: Scherrer MAR, Rocha VB. Increasing trend of sensitization to Methylchloroisothiazolinone/methylisothiazolinone (MCI/MI). An Bras Dermatol. 2014;89(3):527-8. 